\title{
Helicase POLQ-Like
}

National Cancer Institute

\section{Source}

National Cancer Institute. Helicase POLQ-Like. NCI Thesaurus. Code C113139.

Helicase POLQ-like (1101 aa, 124 kDa) is encoded by the human HELQ gene. This protein plays a role in ATP-dependent DNA helicase activity. 